\title{
The Recognition of College Students in the Social Welfare Major in the Direction of Multicultural Family Support Policy in Korea
}

\author{
Su Sun Park
}

\begin{abstract}
The purpose of this study is to investigate the future development of multicultural family support center through the integrated research methodology of quantitative and qualitative analysis that integrates the data analysis of the statistics office of the multicultural family policy and the interview of the college student of the social welfare major. We will produce data that can contribute to the improvement of multicultural family policy and service delivery system And Focus Group Interview (FGI) was conducted in order to be a basis for policy direction based on the awareness of multicultural family support for students of social welfare major. The social welfare major students attending FGI were composed of 3 female students, 3 male students and 4th grade students, who completed courses related to multicultural family support program at Cheongju $S$ University. The direction of the multicultural family support policy recognized by college students in social welfare is to include the concept of multiculturalism within the range of various families and define the meaning of multiculturalism as a multicultural family. In order to do so, social recognition needs to be changed in a way that recognizes diversity. The role of the delivery system for supporting multicultural families, including the Multicultural Family Support Center, should be divided into urban, rural, and urban and rural complexes based on the region. It is necessary to focus on supporting multicultural families in the early stages of multicultural family formation. And that it is necessary to support various services to a wide range of subjects. Within the first three years after marriage, intensive family integration education will help understanding cultural differences and marriage, and above all, Korean language one and two levels of intensive education are needed to prevent problems caused by language differences
\end{abstract}

Keywords : College Students, Direction of Multicultural Family Support Policy, Focus Group Interview (FGI), Multicultural families, Social Welfare Major

\section{INTRODUCTION}

Increase in human exchange due to globalization, deepening economic disparity, and natural disasters have increased population migration among countries. In 2008, the Multicultural Family Support Act was enacted by sticking to the unique policy of family support, which was centered on the marriage of multicultural families in Korea. The number of multicultural families in 2020 is estimated at 1 million [1]. In the future, multicultural families will continue to increase as a result of low fertility, aging, globalization, and inequality in the sex ratio of the marriage age population, and the

Revised Manuscript Received on July 22, 2019.

Su-Sun Park, Dept. Social Welfare, Seowon University, Cheongju City, 28674, Korea..sunybono@seowon.ac.kr

population including married immigrants and their children in 2050 is expected to exceed 5\% of the total population [2].

The perspective to view the welfare of family, which is the most conservative group among those organizing Korea and primary individual group, amid the emergence of conversation topic on diversity globally, has been significantly changed since the foundation of Multicultural Families Support Act in 2008. Multicultural family means to consist of the family by international marriage of Korean with the foreigner, and most of the multicultural families in Korea are organized with foreign wives and Korean husbands. Patriarchal and blood-centric family cultures in Korea consider the social discrimination for the multicultural families basically, hence, multiple policies to support the multicultural families have been performed targeting them as the subjects of welfare protection, which contributed significantly to limit the image of multicultural families in Korea as the welfare subjects. However, the present multicultural families with 960,000 members in 2017 [3], when 10 years passed since the foundation of Multicultural Families Support Act, have been positioned as the major subject in the family welfare policies. The study to review the perception of the university students majoring in social welfare, who will have the jobs after their graduations to provide the social welfare services along with the related policies in the subjects with multicultural families, on the supporting systems for multicultural families has the meaning to provide the fundamental data to seek the future directions and progression plans of multicultural family policies upon investigating the preliminary social workers' level of understanding on the fields of services for multicultural families.

Multicultural Family Support Centers established based on the 'Multicultural Family Support Act' enacted in 2008 in the nationwide municipal districts exist as a delivery system and actively promote multicultural family support projects nationwide.

To establish the supporting system of sociocultural adaptation for the married immigrant families, 21 'Supporting centers for married immigrant families' were designated and operated by regions. With respect to the policies for multicultural family support in Korea, there are 218 multicultural family support centers nationwide including city and county based ones with the main responsible division of Ministry of Gender Equality and Family.

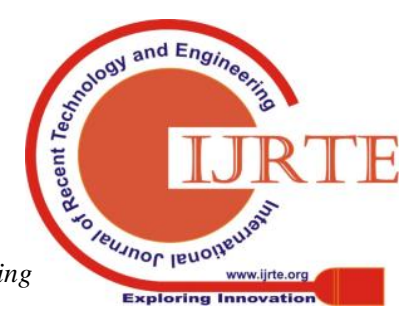


According to the Korean Institute for Healthy Family [1], the recognition of multicultural family support centers was high at 71.4 percent, and 46.2 percent had experience with more than one education and support service, indicating that the multicultural support center is becoming a major delivery system for multicultural families. However, despite the multi-cultural efforts of the government, many studies have raised the issue of the effectiveness and practicality of multicultural family policies, which has been criticized as laws and policies that have not adequately reflected the characteristics and problems of various types of international immigrants and their families [4]. On the other hand, recent studies have raised the issue of the need for diverse approaches considering the period [5, 6,7,8 9] of settling Korean society for multicultural families and the characteristics of family and region. As a result, the Ministry of Gender Equality and Family has diverse discussions on the role and construction of an efficient delivery system through the business analysis of the Multicultural Family Support Center. At the time when the 2 nd basic plan for multicultural families is implemented, it is necessary to devise a policy direction for multicultural families, including methods for diagnosing and operating multicultural family projects, in line with changing multicultural environments.

The Korean government has performed the systemic supports for multicultural families to enhance their quality of life enough to amend the act 12 times from 2008 to 2017[10].

The purpose of recently amended Multicultural Families Support Act is for the members of multicultural families to live the stable family lives and to perform the role and responsibilities as the society members so as to contribute the enhancement of their quality of lives and social integration. "Multicultural family" means the family corresponding to one of the followings according to the amendment in 2015; A. The family consisting of the married immigrant according to Article 2-3 in Act on the Treatment of Foreigners in Korea and the person who acquires the Korean nationality according to Articles 2 to 4 in Nationality Act; B. The family consisting of those who acquire the Korean nationality according to Article 3 and 4 in Nationality Act[10].

In addition, children and juveniles of multicultural families mean those of 24 years old or younger, aligning the age limit with 'Framework Act on Juveniles.' Upon the amendment of Act on Juveniles' Welfare into Act on Juveniles' Welfare Support in 2018, the supports for the youths of multicultural families are described in Article 18, 'Support on immigrant juveniles' aligning 'Multicultural Families Support Act.' As such, it is the case that the regulations have been amended focusing on the supports to improve the quality of life of multicultural families, children, and juveniles in Korea.

Multicultural families are also included in the situation where the contents of various families are increasing in related subjects such as the theory of family welfare or social welfare practice that university students majoring in social welfare. However, there are still negative perceptions and discrimination against multicultural families in Korean society. Therefore, it is important to understand how multicultural families in social welfare major students think about multicultural families included in various families and how they perceive policy provision. It can be helpful in

providing basic data on the direction of future multicultural family support.

The purpose of this study is to investigate the future development of multicultural family support center through the integrated research methodology of quantitative and qualitative analysis that integrates the data analysis of the statistics office of the multicultural family policy and the interview of the college student of the social welfare major. We will produce data that can contribute to the improvement of multicultural family policy and service delivery system.

\section{MATERIALS AND METHODS}

The data used in this study were analyzed on the distribution of multicultural families among the data on the number of cultural families in 2016 by the Ministry of Public Administration [11] and Security and the multi-family statistics published by the Ministry of Gender Equality and Family in 2018[3]. And Focus Group Interview (FGI) was conducted in order to be a basis for policy direction based on the awareness of multicultural family support for students of social welfare major. The social welfare major students attending FGI were composed of 3 female students, 3 male students and 4th grade students, who completed courses related to multicultural family support program at Cheongju $S$ University. The interviews were conducted twice from October 7 to October 30, 2018, and took 1 hour and 30 minutes to 2 hours for each session. For the ethical consideration of the research participants, the researcher explained the purpose and purpose of the study to the researchers and agreed with them. In the preliminary preparation process, the research participants were informed about the interview items to be used in the FGI, have enough time to think about the problems of this study. Interviews used open - ended questions in three main areas: multicultural family policy, promotion delivery system, and multicultural family business. The data analysis process was performed using the qualitative research analysis software MAXQDA.

The following table 1 is the personal information of the interviewers. All ages ranged from 22 to 24 years and all wanted to be social workers except one who wanted to be a child care teacher.

Table 1: Socio-demographic characteristics of Participants

\begin{tabular}{|c|c|c|c|c|}
\hline Participant & Grade & Sex & Age & Hopeful career \\
\hline A & 4 & male & 24 & Social welfare \\
\hline B & 4 & male & 25 & Social welfare \\
\hline C & 4 & male & 26 & Social welfare \\
\hline D & 4 & female & 22 & Day care teacher \\
\hline E & 4 & female & 23 & Social welfare \\
\hline F & 4 & female & 23 & Social welfare \\
\hline
\end{tabular}

\section{RESULTS AND DISCUSSION}

\section{A. An Analysis of the Multicultural Family Statistics}

In table 2, Multicultural families continuously increased from 2000 have been positioned as the major subjects of multiple family welfare programs in Korea, 
counting 318,948 married immigrants and naturalized citizens in 2016.

Due to the amendment of Multicultural Families Support Act (amended on April 4, 2011 and effective on October 5,
2011), the persons who acquire nationality with other reasons are included into multicultural family beside married immigrants from 2012.

Table2. Status of married immigrants and persons acquired nationality by countries

\begin{tabular}{|c|c|c|c|c|c|c|c|c|c|c|c|c|}
\hline \multirow[t]{2}{*}{ Variable } & \multicolumn{3}{|c|}{ Total } & \multicolumn{3}{|c|}{ A marriage immigrant } & \multicolumn{3}{|c|}{$\begin{array}{c}\text { Married } \\
\text { Naturalized } \\
\text { person }\end{array}$} & \multicolumn{3}{|c|}{$\begin{array}{l}\text { Person who acquires nationality } \\
\text { with other reason }\end{array}$} \\
\hline & Total & Male & Female & Total & Male & Female & Total & Male & Female & Total & Male & Female \\
\hline Nationality & \multicolumn{3}{|c|}{ Total } & \multicolumn{3}{|c|}{ A Marriage immigrant } & \multicolumn{6}{|c|}{ Person who acquires nationality } \\
\hline $\begin{array}{l}\text { acquisition } \\
\text { variable }\end{array}$ & Total & Male & Female & Total & Male & Female & Total & \multicolumn{2}{|c|}{ Male } & \multicolumn{3}{|c|}{ Female } \\
\hline 2016 & 318,948 & 61,544 & 257,404 & 159,501 & 28,728 & 130,773 & 159,447 & \multicolumn{2}{|l|}{32,816} & \multicolumn{3}{|l|}{126,631} \\
\hline 2015 & 294,663 & 56,652 & 238,011 & 144,912 & 25,263 & 119,649 & 93,249 & 10,308 & 82,941 & 56,502 & 21,081 & 35,421 \\
\hline 2014 & 295,842 & 48,787 & 247,055 & 149,764 & 21,953 & 127,811 & 90,439 & 4,261 & 86,178 & 55,639 & 22,573 & 33,066 \\
\hline 2013 & 281,295 & 45,348 & 235,947 & 147,591 & 20,887 & 126,704 & 83,929 & 4,264 & 79,665 & 49,775 & 20,197 & 29,578 \\
\hline 2012 & 267,727 & 42,459 & 225,268 & 144,214 & 19,630 & 124,584 & 76,473 & 4,268 & 72,205 & 47,040 & 18,561 & 28,479 \\
\hline
\end{tabular}

According to the status of the table 3, Korean Chinese were the most prevalent followed by Vietnamese and Chinese. This distribution has been going the same since 2013.

Table 3. The Status of Married Citizens by Nationality

\begin{tabular}{|c|c|c|c|c|}
\hline Nationality & 2013 & 2014 & 2015 & 2016 \\
\hline $\begin{array}{c}\text { China } \\
\text { Korean) }\end{array}$ & 100,524 & 103,194 & 103,171 & 110,619 \\
\hline China & 67,944 & 71,661 & 59,813 & 64,524 \\
\hline Vietnam & 52,323 & 56,332 & 62,072 & 66,554 \\
\hline Philippines & 15,256 & 16,473 & 17,576 & 18,247 \\
\hline Japan & 12,338 & 12,875 & 11,391 & 11,278 \\
\hline Cambodia & 5,684 & 6,184 & 6,902 & 7,221 \\
\hline Mongolia & 3,186 & 3,257 & 3,308 & 3,394 \\
\hline Thailand & 2,975 & 3,088 & 3,069 & 3,328 \\
\hline $\begin{array}{c}\text { The United } \\
\text { States }\end{array}$ & 3,081 & 3,350 & 5,368 & 7,377 \\
\hline Russia & 2,025 & 1,976 & 1,937 & 1,895 \\
\hline Taiwan & 2,661 & 2,953 & 4,298 & 4,552 \\
\hline The rest & 13,298 & 14,499 & 15,758 & 19,959 \\
\hline Total & 281,295 & 295,842 & 294,663 & 318,948 \\
\hline
\end{tabular}

Source:2018 Multicultural Family Statistics Ministry of Gender Equality and Family

\section{B. FGI Analysis Results}

\section{Multicultural Family Policy}

The direction of the multicultural family support policy recognized by college students in social welfare is to include the concept of multiculturalism within the range of various families and define the meaning of multiculturalism as a multicultural family. In order to do so, social recognition needs to be changed in a way that recognizes diversity.

Now, I think the direction of support for multicultural families should be talked about in the community-oriented culture of the region... ...that we live together, not in the way of giving the benefit to anyone. (participant B).

I think social integration is something that both sides have to move with an open mind. Now, I think that's the way we're going to go about the multiculturalism. (participant $C$ ).

Propulsion delivery system

The role of the delivery system for supporting multicultural families, including the Multicultural Family Support Center, should be divided into urban, rural, and urban and rural complexes based on the region. Of course, in order to prevent duplication of projects that support various multicultural families, it is necessary to have an organization such as a multicultural family support center that can serve as a control tower, and it is necessary to strengthen the power so that the center can play its role.

When you look at multicultural families, you have to look at them as one of the various families. Not to be divided into Korean families and multicultural families all the time... but now that children of multicultural families are growing up with our children, how long will they share it with our children... and so should the delivery system for multicultural families. (participant A).

The support system should be operated differently to meet the local situation of multicultural families. It has a control tower and is operated locally under it.... ( participant D).

\section{Multicultural Family Support Project}

It is necessary to focus on supporting multicultural families in the early stages of multicultural family formation. And that it is necessary to support various services to a wide range of subjects.

I think we need to focus on learning languages in the early stages, not always on the multicultural families( participant $F)$.

I think it is right for multicultural families to provide different support in line with their development cycles. ( participant E).

\section{CONCLUSION}

It is necessary to provide customized support for the target by classifying it according to the adaptation stage of multicultural family. Within the first three years after marriage, intensive family integration education will help understanding cultural differences and marriage, and above all, Korean language one and two levels of intensive education are needed to prevent problems caused by language differences. It is also necessary to accommodate multicultural families as one of the various family types and to implement support policies in the same context as other family types. 


\section{REFERENCES}

1. Korean Institute for Healthy Family. Status of multicultural family support center for 2013.

2. Y.G, Kim, H.M Choi., G.H Kim., S.M, Sung, "Study on change of multicultural family and social countermeasure". Korea institute for health and social affairs. 2012.

3. Statistics on multicultural families in 2018, Ministry of Gender Equality and Family, 2018.

4. A. L, Jang, "Perceived policy and legal rights of multicultural children: from the stance of native Korean peers", Multiculture and Peace, 12(1), 2018, pp.31-58,

5. S.M, Kim, “The Retrospective Consideration for 'Korean' Multicultural Policy and Practice", Social studies education, 50(4), 2011, pp.171-188,

6. J.Y. Kim, C.G. Kang, E.C. Lee, "Closed Korea: Perceptions and policies on multi-culture in Korea”, Issue Brief, 4(2), 2014, pp. 1-16.

7. K.S. Jung, S.M. Lee, S.H. Kim, S.I. Park. A study on the attitudes related to national identity and immigrations in Koreans, IOM Immigration Policy Institute. 2010.

8. Y.G. Chae. "Reanalysis for changing process of multicultural society", Press and Society, 17(2), 2009, 49-86.

9. J.K. Kang, "A research of the multicultural education on the perception of multi-culture in the university students", Multicultural Contents Research, 12, 2008, pp53-77.

10. National Legal Information Center. 2019. Available from http://www.law.go.kr/lsInfoP.do?lsiSeq=199550\&efYd=20180613\#00 00(website)

11. Ministry of Public Administration and Security. Foreign residents status survey. 2016.

\section{AUTHORS PROFILE}

SU SUN PARK, August 2004: Department of Home Care at Sookmyung Women's University Graduate School (Ph. D.) March 2012 Present: Professor of Social Welfare at Seowon University In the field of interest: family, middle-aged people, social welfare practice E-Mail:sunybono@seowon.ac.kr 